\title{
Assessing Stability and Dynamics in Flood Risk Governance
}

\section{An Empirically Illustrated Research Approach}

\author{
Dries L. T. Hegger • Peter P. J. Driessen • Carel Dieperink • \\ Mark Wiering • G. T. Tom Raadgever • Helena F. M. W. van Rijswick
}

Received: 5 August 2013 / Accepted: 16 June 2014 /

Published online: 26 June 2014

(C) Springer Science+Business Media Dordrecht 2014

\begin{abstract}
European urban agglomerations face increasing flood risks due to urbanization and the effects of climate change. These risks are addressed at European, national and regional policy levels. A diversification and alignment of Flood Risk Management Strategies (FRMSs) can make vulnerable urban agglomerations more resilient to flooding, but this may require new Flood Risk Governance Arrangements (FRGAs) or changes in existing ones. While much technical knowledge on Flood Risk Management is available, scientific insights into the actual and/or necessary FRGAs so far are rather limited and fragmented. This article addresses this knowledge gap by presenting a research approach for assessing FRGAs. This approach allows for the integration of insights from policy scientists and legal scholars into one coherent framework that can be used to identify Flood Risk Management Strategies and analyse Flood Risk Governance Arrangements. In addition, approaches for explaining and evaluating (shifts in) FRGAs are introduced. The research approach is illustrated by referring to the rise of the Dutch risk-based approach called 'multi-layered safety' and more specifically its application in the city of Dordrecht. The article is concluded with an overview of potential next steps, including comparative analyses of FRGAs in different regions. Insights in these FRGAS are crucial to enable the identification of action perspectives for flood risk governance for actors at the level of the EU, its member states, regional authorities, and public-private partnerships.
\end{abstract}

D. L. T. Hegger $(\bowtie) \cdot$ P. P. J. Driessen • C. Dieperink

Environmental Governance, Copernicus Institute of Sustainable Development, Utrecht University, PO Box 80115, 3508 TC Utrecht, The Netherlands

e-mail: d.l.t.hegger@uu.nl

M. Wiering

Department Geography, Planning and Environment, Group Political Sciences of the Environment, Radboud University Nijmegen, Institute for Management Research (IMR), PO Box 9108, 6525 GD Nijmegen, The Netherlands

G. T. T. Raadgever

Grontmij Nederland BV, Division Transportation \& Mobility, Department of Hydraulic Construction, Team Coastal and Rivers, De Holle Bilt 22, 3732 HM De Bilt, The Netherlands

H. F. M. W. van Rijswick

Utrecht Centre for Water, Oceans and Sustainability Law, Utrecht School of Law, Achter Sint Pieter 200, 3512 HT Utrecht, The Netherlands 
Keywords Flood risk management strategies - Europe - Dordrecht - Resilience - Legitimacy Efficiency $\cdot$ Effectiveness $\cdot$ Flood risk governance arrangements

\section{Introduction}

Climate change is expected to result in sea-level rise and to induce more extreme weather events, causing modifications in the frequency, severity and duration of hydro-meteorological hazards (IPCC 2011). Population growth, economic growth, urbanisation and in some cases also soil subsidence (Mitchell 2003) exacerbate these potential consequences. In Europe, flooding, together with landslides, is the most frequently experienced natural hazard, and accounts for the largest number of casualties and most economic damage (Guha-Sapir et al. 2013). Urban areas in particular face increasing flood risks. ${ }^{1}$

In 2007 the European Union issued its Floods Directive, which requires that Member States take into account the consequences of floods next to their probability (Kellens et al. 2013). The directive primarily stresses the importance of Flood Risk Management Strategies (FRMSs) such as prevention, mitigation and preparedness, but it has been shown that actors in some countries have started to take into account response and recovery strategies as well (ibid). FRMSs can be defined as approaches for dealing with flood risks which can be distinguished from one another by their focus on the probability of flooding, its consequences or on recovery after a flood has struck. Both at the level of the EU and in EU Member States (e.g. http://www. helpdeskwater.nl/algemene-onderdelen/serviceblok/english/water-and-safety/, accessed 11 February 2014), it is assumed that urban agglomerations vulnerable to flooding will be more resilient to flooding if multiple FRMSs are applied simultaneously and are aligned (Aerts et al. 2008; Wardekker et al. 2010; Van den Brink et al. 2011). We argue that a resilient urban agglomeration is one in which several different FRMSs are applied simultaneously, linked together and aligned, whereby it is assumed that this application and combination of multiple strategies increases society's capacity to cope with flood risks in an effective way. This understanding of resilience comes close to notions of social-ecological and evolutionary resilience (Folke 2006; Steinführer et al. 2009; see Davoudi et al. (2012) for a literature review on the use of the concept of resilience).

For a long time a natural and technical science perspective has dominated the research on FRMSs in Europe, focusing on, amongst others, risk assessment, future scenarios, technical measures, and early warning systems (http://www.irma-sponge.org; http://www.floodsite.net/; http://www.hydrate.tesaf.unipd.it, accessed 11 February 2014). Many research initiatives have been taken in an effort to address water-related risks (Quevauviller 2011), including research on climate projections, consequences of climate change for water cycles and ecosystems and research into extreme floods (ibid). Although some projects, like NeWater, FLOODsite and CORFU, have addressed social-scientific research questions, social-scientific, governance and legal studies on flood risk management are still rare, fragmented and limited in scope. A systematic comparative analysis of Flood Risk Governance Arrangements (FRGAs) is still

\footnotetext{
${ }^{1}$ Between 2000 and 2005, Europe suffered more than 100 floods, including nine major flood disasters. Besides economic losses of more than $€ 35$ billion, these floods also caused 155 casualties. Events causing a high number of fatalities were the floods in Romania in 2005 ( 85 fatalities) and the 1998 disaster in Slovakia (54 fatalities). Large economic losses were caused by floods in the Elbe basin in 2002 (over EUR 20 billion), in Italy, France and the Swiss Alps in 2000 (around EUR 12 billion), and a series of those in the United Kingdom during the summer of 2007 (accumulated losses exceed EUR 4 billion) (Barredo 2007). Also the 2013 floods in central Europe (14 casualties and significant economic damage) and recent flood experiences in the UK demonstrate the actual threat of floods in Europe.
} 
absent and especially legal aspects (such as liability, formal competence, regulatory approaches and compliance etc.) have hardly been addressed.

Furthermore, water governance research in general and flood risk governance research in particular can be said to be fragmented in its aims and scopes (Araral and Wang 2013; Wiering and Arts 2006). Some researchers have addressed the question what kind of institutional change is taking place (e.g. Wiering and Arts 2006; Hartmann and Driessen 2014), but few of them provide encompassing analyses combining multiple dimensions of FRGAs. Also studies focused on explaining (e.g. Brouwer and Biermann 2011) or evaluating water governance (e.g. Van Buuren et al. 2013) exist, as well as legal analyses (e.g. Van Rijswick and Havekes 2012). But to the best of our knowledge, comparative multidisciplinary studies that combine the steps of analysing, explaining and evaluating Flood Risk Governance Arrangements are lacking.

Insight in FRGAs - the actors, discourses, rules and resources through which Flood Risk Management Strategies are developed and put into practice - is needed to be able to understand and guide the implementation of a diverse range of FRMSs (Meijerink and Dicke 2008; Wiering and Arts 2006). It can be argued that the implementation of a diversified, resilient, set of FRMSs in a certain area is only possible if these strategies and their coordination are considered legitimate, effective and efficient given the opportunities and constraints of their physical and social context. Whether implementation is indeed done in accordance with these criteria is an empirical question that will be answered differently in different contexts.

This paper aims to make a step towards the formulation of concrete recommendations for achieving legitimate, efficient and effective FRGAs, including guidelines regarding their applicability in different contexts ("design principles" in Ostrom's (1990) terms). It does so by presenting a research approach consisting of the four steps of i) identifying FRMSs (section 2), ii) analysing (section 3), iii) explaining (section 4) and iv) evaluating FRGAs (section 5). The usefulness of the approach will be illustrated with a case study, the application of the Dutch policy concept of multi-layered safety in the city of Dordrecht. The case study as well as the methods used for researching it is introduced in section 6. Section 7 presents and discusses the results of the case study analysis. Section 8 concludes the paper.

\section{Step one: Identifying a Diversification in Flood Risk Management Strategies (FRMSs)}

To protect urban agglomerations from flooding, several types of FRMSs are being discussed and/or implemented in practice. European policies including the Floods Directive distinguish between prevention, protection, preparedness, emergency response, and recovery (http://ec. europa.eu/environment/water/flood_risk/flood_risk.htm, accessed 19 July 2013). Also several finalised and on-going European projects make a distinction between different types of strategies (Oosterberg et al. 2005; Klijn et al. 2009; Djordjevic et al. 2011; Hegger et al. 2013). Drawing on these categorisations, we distinguish between the five types of FRMSs depicted in Table 1. These FRMSs focus on the probability of flooding (Flood Defence); on the potential consequences of flooding (Flood Risk Prevention, Flood Risk Mitigation, Flood Preparation) and on recovery after a flood has struck (Flood Recovery).

Not each way of diversifying FRMSs will be feasible everywhere. Apart from geographical and technical factors, this feasibility will also depend on the Flood Risk Governance Arrangements through which FRMSs are attempted to be implemented. Countries and regions in the EU have been shown to differ significantly, amongst other things, with regard to administrative structures and cultures, and historical pathways in dealing with floods (Hegger et al. 2013). In addition, diversification of FRMSs may imply that new actors get a role in flood risk management adding complexities and potential conflicts of interest (ibid; 
Table 1 Five types of Flood Risk Management Strategies (FRMSs)

\begin{tabular}{|c|c|}
\hline Strategy & Explanation \\
\hline Flood defence & $\begin{array}{l}\text { Flooding can be prevented by infrastructural works, such as dikes, dams, embankments and } \\
\text { weirs, upstream retention or giving more space to the river within its current embankments } \\
\text { ("keeping water away from people"), mostly referred to as "flood defence" or "structural } \\
\text { measures". Main actors: generally governmental water management actors at national/ } \\
\text { regional level. }\end{array}$ \\
\hline $\begin{array}{l}\text { Flood risk } \\
\text { prevention }\end{array}$ & $\begin{array}{l}\text { Negative consequences of flooding can be avoided by proactive spatial planning or land use } \\
\text { policies ("keeping people away from water"), aimed at building only outside areas that are } \\
\text { prone to flooding. Main actors: actors involved in planning processes (governmental } \\
\text { actors, private parties). Flood insurance companies may influence planning decisions, for } \\
\text { instance by (not) insuring properties in high-risk areas or the use of risk-based premiums } \\
\text { (Kunreuther 2008). }\end{array}$ \\
\hline $\begin{array}{l}\text { Flood risk } \\
\text { mitigation }\end{array}$ & $\begin{array}{l}\text { Consequences of floods can be mitigated by a smart design of the flood-prone area. Measures } \\
\text { include spatial orders, constructing flood compartments, or (regulations for) flood-proof } \\
\text { building. Main actors: citizens, project developers, water managers and other public and } \\
\text { private actors. }\end{array}$ \\
\hline $\begin{array}{l}\text { Flood } \\
\text { preparation }\end{array}$ & $\begin{array}{l}\text { Consequences of floods can also be mitigated by preparing for a flood event. Measures } \\
\text { include developing flood warning systems, preparing disaster management and evacuation } \\
\text { plans and managing a flood when it occurs. Main actors: governmental organisations like } \\
\text { the meteorological office, flood forecasting centres, local and regional governments. }\end{array}$ \\
\hline Flood recovery & $\begin{array}{l}\text { This strategy facilitates a good and fast recovery after a flood event. Measures include } \\
\text { reconstruction or rebuilding plans as well as compensation or insurance systems. Main } \\
\text { actors: national governments establishing disaster relief funds, insurance companies as } \\
\text { well as the affected citizens themselves. }\end{array}$ \\
\hline
\end{tabular}

Meijerink and Dicke 2008). Thus, efforts at a broadening of FRMSs will likely require new Flood Risk Governance Arrangements, changes in existing ones, or the establishment of links between formerly separate arrangements. A first step in understanding and guiding developments in FRGAs will be to analyse the stability and dynamics therein.

\section{Step two: Analysing Stability and Dynamics in Flood Risk Governance Arrangements}

To analyse stability and dynamics in Flood Risk Governance Arrangements, we propose to use the Policy Arrangements Approach (PAA). Policy arrangements have been defined as "a temporary stabilisation of the content and organisation of a policy domain" (Van Tatenhove et al. 2000). By studying the development of these policy arrangements over time, the degree of stability or dynamics in these arrangements can be analysed. The PAA claims to link up all relevant dimensions of a policy domain (actors, discourses, rules and resources) and hence enables a study of the policy arrangement as a whole. The approach has been applied in earlier studies of environmental policies, nature conservation and water management (Van Tatenhove et al. 2000; Arts et al. 2006; Wiering and Arts 2006). Two features make the approach particularly useful for analysing FRGAs. First, the approach combines and integrates different concepts within frameworks of policy analysis (e.g. policy network models, discourse analysis, the advocacy coalitions framework and regime theory in international relations) and includes both structure and agency - related elements of institutional analysis, thus choosing a more sociological approach (Giddens 1984). Other approaches are less comprehensive in terms of the dimensions that are included. Second, as is shown in Table 1 below, the four dimensions of the PAA allow for the inclusion and integration of legal factors in the analysis. 
Flood Risk Governance Arrangements (FRGAs) can be defined as institutional constellations resulting from an interplay between actors and actor coalitions involved in all policy domains relevant for flood risk management - including water management, spatial planning and disaster management; their dominant discourses; formal and informal rules of the game; and the power and resource base of the actors involved (Hegger et al. 2013). FRGAs can be analysed at different scales, including local, regional, national and international. Table 2 presents an operationalization of FRGAs based on the four dimensions of the PAA. The indicators specified include indicators previously defined by Wiering and Arts (2006) and - in italic - additional, predominantly legal, factors added by us.

Patterns may exist in the relationship between FRMSs and FRGAs. For instance: in Flood Risk Prevention is mainly based on more pro-active spatial measures, requiring a strong role of spatial planning, while Flood Defence, based upon measures like the constructions of dams, dikes and embankments, requires an elaborate water management sector. The involvement of market parties - the public-private divide - differs between the FRMSs and is strongly dependent on the political and constitutional tradition of a state (Meijerink and Dicke 2008; Keessen et al. 2013). Private parties often play a role in flood recovery, but in different ways. Obviously, new FRMSs will result in changes in actors, rules, power and discourses. These changes in FRGAs should be analysed longitudinally to acquire insights in the degree of stability and dynamics therein.

\section{Step Three: Explaining Stability and Dynamics in Flood Risk Governance Arrangements}

After analysing stability and dynamics in FRGAs (what happened?), stability and dynamics should also be explained (why did it happen?) to find out to what extent they can be changed at will. Literature from the policy sciences points at a wide range of issues that need to be taken into account, including, at least, the importance of structure vs. agency (Capano and Howlett 2009; Giddens 1984), the extent to which change is coming from within or outside a specific governance arrangement (Capano and Howlett 2009) and the degree to which change is conceptualised as incremental or radical (ibid). As a first step towards an explanatory framework, we propose a distinction between the following four types of explanatory factors:

Table 2 Operationalization of the Flood Risks Governance Arrangements concept (based a.o upon Wiering and Arts 2006). The italic sub-dimensions have been added to the original framework

\begin{tabular}{llll}
\hline Actors & Discourses & Rules & Power \& Resources \\
\hline Public actors & $\begin{array}{c}\text { Relevant scientific } \\
\text { paradigms and } \\
\text { uncertainties }\end{array}$ & $\begin{array}{c}\text { Legislation (including } \\
\text { jurisprudence/case law) }\end{array}$ & $\begin{array}{c}\text { Legal authority, including the } \\
\text { right to regulate property } \\
\text { (regulation, compensation } \\
\text { and expropriation) }\end{array}$ \\
Private actors & $\begin{array}{c}\text { Policy programmes, } \\
\text { policy objectives } \\
\text { and policy concepts }\end{array}$ & $\begin{array}{c}\text { Constitutional, procedural } \\
\text { and substantive norms }\end{array}$ & Financial power \\
$\begin{array}{c}\text { Historical metaphors/ } \\
\text { narratives } \\
\text { oppositions }\end{array}$ & $\begin{array}{c}\text { Legal instruments } \\
\text { Policy and legal values } \\
\text { and principles }\end{array}$ & Legal traditions & Knowledge \\
& & Informal rules & Interaction skills \\
\hline
\end{tabular}


- Physical circumstances (seasonality of rainfall patterns, climate change trends; altitude, gradient, the degree of complexity of river systems) determining the nature and characteristics of flood events. Actors cannot change these physical circumstances at will and changes therein take at least several decades (e.g. climatic conditions) but often millennia (altitude, gradient) to materialise. For the short term, physical circumstances should therefore be seen as unchangeable background conditions contributing more to stability than to dynamics in FRGAs;

- Physical and social infrastructure (the presence of dams, dikes, sewer systems, railways, ships, houses; but also educational systems, including handbooks and training facilities, and knowledge infrastructure). In terms of the dimensions of the PAA, physical and social infrastructures can be considered "precipitated resources". Due to large past investments (billions of Euros), they have gained momentum (Hughes 1987). This momentum powerfully reinforces path-dependency and lock-in. Infrastructure can be expected to enable some FRMSs by providing the necessary capabilities, but to constrain others. The chance that new FRMSs will actually be implemented is probably enhanced in cases in which the new strategies make use of infrastructures that are already in place;

- Agency, or the purposeful actions of knowledgeable and capable agents (e.g. policy entrepreneurs), forms a third explanatory factor (Kingdon 1984; Brouwer and Biermann 2011; Huitema and Meijerink 2010). Agency is generally assumed to be an important contributor to dynamics in governance arrangements (ibid) but it may also be used to obstruct change. It is therefore an empirical question, when, how and why agency contributes to stability in FRGAs and when, how and why it contributes to dynamics therein;

- Shock events. Flood consciousness has been shown to vary greatly between regions, predominantly depending on the presence and memory of catastrophic events (e.g. Downs 1972). A flood is an external shock, which creates a disturbance throughout the interconnected ecological, economic and social systems (Green et al. 2011). Shock events may lead to major, but temporary, changes in public opinion or governmental priorities (Downs 1972), accelerating policy change. For instance, in The Netherlands, in 1995, an emergency situation arose because of the threat of dikes being breached due to extremely high water levels in some major rivers. As Driessen and De Gier have shown (1999), this shock event helped the implementation of new legislation and flood defence measures, which had been hoped for by many water professionals for some time. In this specific example, however, the main thrust of the change was acceleration along existing paths and trajectories (flood defence), although a long-standing call to give consideration to natural and historical landscapes was taken into account for the first time. Only a few authors attempted to sketch the conditions in which shock events might contribute to path-breaking change (Dieperink 2000; Wiering 2008).

Through in-depth and more comparative empirical research, we expect it to be possible to gain insight into the relative importance of these explanatory factors, and hence into possible action perspectives. However, literature on policy change suggests that the margins for establishing change are small and that dominant institutional arrangements have some degree of stability, inertia and predictability (Kingdon 1984; Sabatier and Weible 2007). The latter may on one hand facilitate existing FRMSs, thus offering (legal) certainty on the division of risks and responsibilities, but it may on other hand complicate the implementation of new strategies or the establishment of links between different strategies (Pahl-Wostl 2009; Keessen and Van Rijswick 2012). However, before concrete recommendations can be derived, it is first necessary to evaluate FRGAs. 


\section{Step Four: Evaluating FRGAs}

As indicated in the introduction, our research approach is based on the assumptions (i) that a diversification of FRMSs makes urban agglomerations more resilient to flood risks and (ii) that this requires legitimate, efficient and effective FRGAs. It is proposed to use the concepts of resilience, legitimacy, efficiency and effectiveness, first, as success criteria for assessing whether and to what extent actors in vulnerable urban regions actually managed to diversify, link and align FRMSs (contributing to resilience) as well as whether the strategies and their coordination were indeed legitimate, efficient and effective. Second, it is necessary to challenge these starting assumptions, and eventually, nuance them. For instance, in terms of our assumption about resilience, implementation and coordination of all five FRMSs would be an ideal to aspire to. But one can logically assume that this is not always necessary or possible. In a very sparsely populated area it would be less essential to have sound evacuation plans (flood preparation). Legitimacy, efficiency and effectiveness are conceptualised as follows:

- Legitimacy (Paavola 2008; Van Buuren et al. 2013) refers to the extent to which governance arrangements secure the rule of law and ensure transparency, accountability and participation of national and regional public and private actors. For instance, is the voice of minority groups heard (e.g. inhabitants of emergency retention areas)? Are governments legally authorized to regulate property rights?

- Efficiency refers to the extent to which public and private resources have been used in a cost-efficient way. For instance, do FRGAs adequately deal with uncertainty about the regional consequences of climate change (see also Adger et al. 2003). Also the costs of cooperation and coordination (transaction costs) should be considered. FRMSs should ideally be linked together and aligned in a smart way, minimising the time and effort required for the coordination, but it is still an open question how the latter can best be achieved. In any case, transaction costs should be compared with the benefits of cooperation and coordination. These may include improved safety, avoidance of flood damage but also the possibility to achieve the same safety level or the same standard of economic protection in a more efficient way through smart combinations of FRMSs.

- With effectiveness we refer to the extent to which flood risks and related vulnerabilities are actually reduced e.g. through a variety of region- and context-specific norms, instruments, processes and strategies. It can be tried to assess what existing FRGAs mean for the risks and vulnerabilities faced by specific actors. Also the role of risk perception (e.g. flood awareness) in this should be looked upon. One could argue that effective FRGAs should ensure both that citizens are safe and that they feel safe, although flood awareness could also be instrumental in that it may lead to support for new measures (Adger et al. 2003).

Legitimacy, efficiency and effectiveness of FRGAs can be evaluated by confronting normative ideas of what is needed in a specific case with empirical evidence. It is an open question, as to whether required changes in FRGAs in a specific context will be small or large.

\section{Dordrecht: An Empirical Illustration of Flood Risk Governance in The Netherlands}

This section introduces the paper's case study methods (6.1) and subsequently provides an indepth introduction of the case study area (6.2). 


\subsection{Methods}

The aim of this paper's case study is to give an initial illustration of how the approach can be used in empirical studies. The paper's scope does, however, not allow an elaborate empirical analysis in which all the aforementioned research steps (identification, analysis, explanation, evaluation) are addressed in detail. The approach will be used to explore recent developments in flood policies in the Dutch region of RijnmondDrechtsteden, in the southern part of the Randstad, the prime West coast urban agglomeration in The Netherlands, zooming in on a specific area called the Island of Dordrecht. In this case study, actual dynamics in flood risk governance are taking place, providing material for illustrating the application of our approach. For our data collection, we relied on document analyses of the empirical case, our knowledge of related case studies within projects investigating Dutch climate adaptation (Knowledge for Climate change), pilot studies of the Dutch policy program on Adaptation (Dutch Delta programme) complemented with insights of two employees of the municipality of Dordrecht.

\subsection{The Island of Dordrecht in the Rijnmond Drechtsteden Area}

The Island of Dordrecht is, together with the city of Rotterdam, a number of smaller cities and the surrounding agricultural and nature areas, part of the Rijnmond-Drechtsteden area. This area is essential for the Dutch economy (amongst other facts thanks to the harbour of Rotterdam). Due to its location in the estuaries of the Rhine and Meuse it is also of great ecological importance. At the same time, however, 1.6 million people need dikes to protect them against floods from rivers and from the sea, while 64,000 people are living outside dikeprotected areas (Programmateam Rijnmond-Drechtsteden 2012). The Island of Dordrecht (9,000 ha, 119,000 inhabitants) has one so-called dike ring (a single dike protected area) and one municipality (Dordrecht). However, part of the island, including parts of the city centre, lies outside the dike-protected area. The island is vulnerable to flooding as it is a river island enclosed by the Old and the New Meuse, the Merwede, New Merwede and the Hollandsch Diep. Bridges, tunnels and shipping connect the island to the mainland. The island consists of both urban and rural areas.

Dordrecht faces significant flood risk (Hoss 2010) which are expected to increase. If flooding occurs, it will be deep and fast. Under present circumstances, the expected number of casualties in case of flooding will be 300 and the material damage is expected to be 7 billion Euros (Programmateam Rijnmond-Drechtsteden 2012). The probability of flooding is expected to increase due to sea level rise, an increase in extreme river discharges and land subsidence. Furthermore, the economic value of the area-currently 15 billion Euros (Gersonius et al. 2012:10) is expected to increase due to urban (re) development and improvement of transport infrastructure. In addition, the creation of natural areas is expected to continue (ibid).

\section{Assessing Stability and Dynamics}

\subsection{Identifying FRMSs in Dordrecht}

A large part of the Island of Dordrecht $(7,000 \mathrm{ha})$ is protected against flooding by the primary flood defences, with a legally prescribed maximum yearly probability of overtopping of 
$1: 2,000 .^{2}$ The remaining 2,000 ha, including the historical port, parts of the historical centre and more recent housing and business areas, are not protected against flooding by law. Protection against flooding in these 'outside dike areas' (buitendijkse gebieden) is not a government responsibility (more specific of the water authorities), but that of the inhabitants. However, it is the responsibility of the local government to take care of appropriate ("good") spatial planning that takes flood risks into account, to set building requirements and prepare evacuation plans. Every two years, the embankments in the port area overflow, sometimes with significant economic damage (as in 2012).

The culturally interesting historical city centre lies partly outside, partly inside and partly on top of the dike (see also Fig. 1) and some houses even function as flood defence themselves. Strengthening this part of the dike - as well as constructive measures just outside the dikewill be problematic as many monumental buildings are situated in the city centre. Within the dike-protected area, old dikes used to divide the island into a few compartments. However, as they are perforated by local roads and other infrastructure they no longer function as flood defence structures. This means that the classical role for flood defence is preferably enlarged with a stronger focus on spatial planning, building requirements and evacuation plans.

Discussions on a broadening of FRMSs in Dordrecht are part of broader discussions on the implementation of the Dutch policy concept of multi-layered safety (MLS), which after its introduction in the National Water Plan of 2009 has become a central element in policy discussions on FRM.

The Island of Dordrecht is a pilot area for the implementation of the MLS approach. The municipality of Dordrecht is playing a relatively pro-active role in flood risk management, at least compared to other Dutch municipalities. As evacuation of the full island is problematiconly $15 \%$ of the residents could escape the island in case of flooding-Dordrecht seeks for solutions on the island itself. Its residents are said to be well-aware of the area's floodproneness and have demonstrated a strong social cohesion and an active citizenship, e.g., by helping each other when necessary and showing solidarity from one part of the area to another. This strengthens the idea that using other FRMSs that explicitly need community support would be feasible on the Island of Dordrecht. The idea of creating a self-sustaining Island of Dordrecht by combining multiple FRMSs has been elaborated - together with other possible strategies - as part of a local study for the Delta programme, an encompassing policy programme focused on long-term flood protection and fresh water availability in The Netherlands. The proposed solution is to move from the current situation, to a more differentiated approach that reorganizes the Island of Dordrecht in compartments with different flood safety regimes, tailored to the possibilities of these different areas. Protection levels will differ between the areas. Table 3 below includes the FRMSs introduced in section 2 and subsequently specifies to what extent the identified FRMSs are addressed in the self-sustaining strategy for the Island of Dordrecht.

\subsection{Analysing Flood Risk Governance Arrangements in Dordrecht}

Table 4 provides an overview of dynamics in flood risk governance arrangements in Dordrecht using the four dimensions of the PAA. The table shows that, as part of a

\footnotetext{
${ }^{2}$ In The Netherlands, primary flood defences have a legally prescribed safety norm expressed in terms of the probability of overtopping, that is the chance that the flood level becomes higher than a certain specified height. The maximum allowed probability of overtopping is currently specified per dike protected area. Throughout The Netherlands, this probability ranges from $1 / 250$ to $1 / 10,000$ and is intended to be lowest in places where the potential consequences of floods are highest (e.g. 1/10,000 in Zuid-Holland).
} 


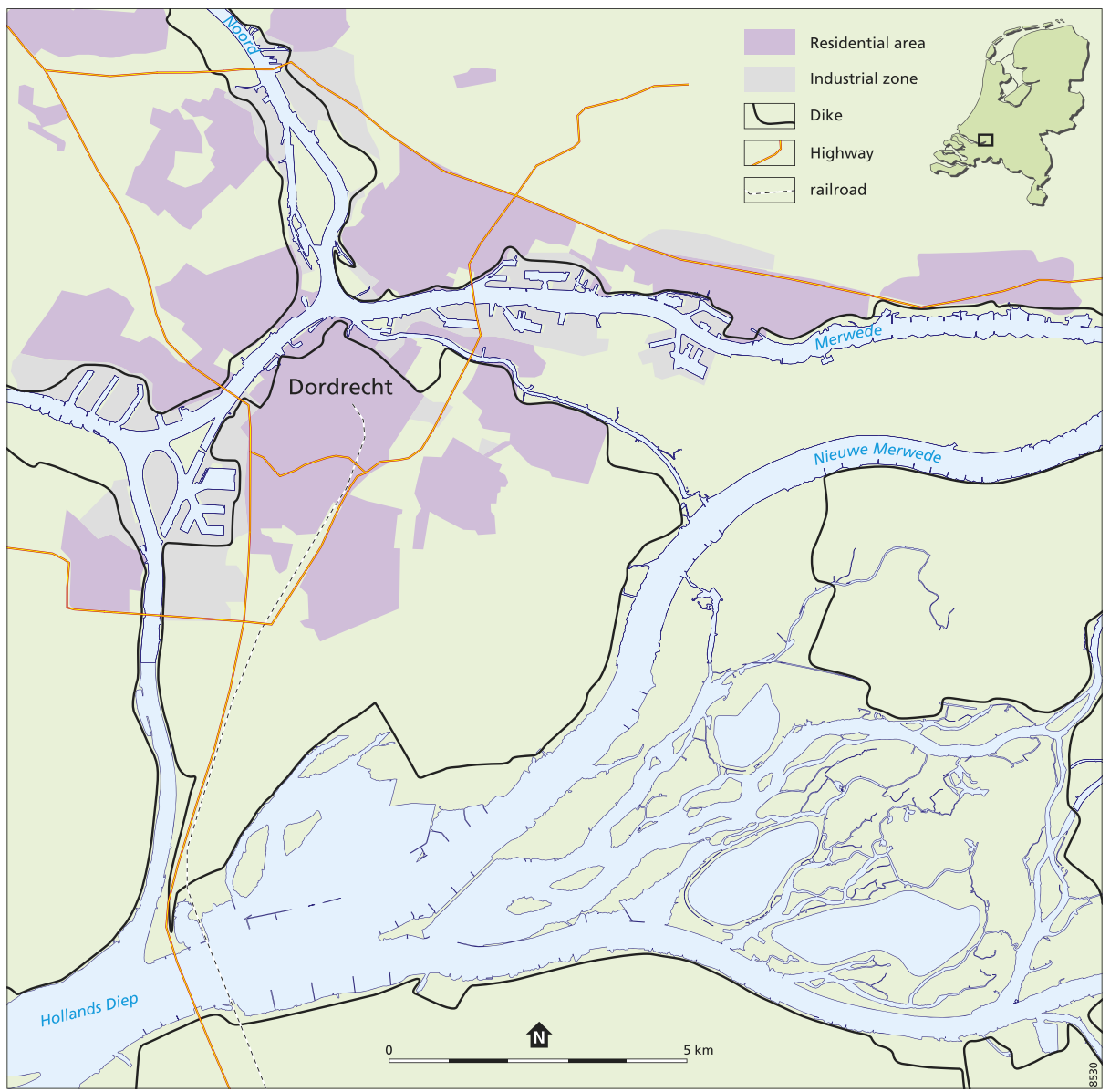

Fig. 1 the island of Dordrecht (upper right corner: position of Dordrecht in The Netherlands)

broader discursive shift to "building with water, living with water and multi-layered safety", in Dordrecht a discursive shift can be witnessed from "battle against the water" to "self-sufficient island of Dordrecht". This discursive shift is mirrored with shifts in actor coalitions. The key actors related to the MLS approach in Dordrecht have joined forces and are now collectively searching for possibilities to materialise the discursive shift by mobilising resources and adapting rules of the game. In terms of resources, important steps have been made through the generation of important knowledge and capacities: networks have been created between the municipality, other governmental actors and knowledge institutes (a learning action alliance) in which, amongst others, knowledge on flood consequences has been created. The Delta programme may provide a window of opportunity for the necessary changes in financing arrangements. Also in the rules of the game dimension, dynamics can be observed, although there are still open questions pertaining to the need to change formal divisions of responsibilities amongst actors (from water authorities to municipalities) and the necessity of and ways in which existing safety norms could be changed. 
Table 3 Identified FRMSs in Dordrecht

Strategy Measures proposed in self-sustaining strategy for the Island of Dordrecht

1. Flood defence

2. Flood risk prevention

3. Flood risk mitigation

4. Flood preparation
Tailor made reinforcement of the primary flood defences is foreseen, including an extra strong delta dike for maximum flood risk reduction;

Reduction of urbanisation in the south of the Island through pro-active spatial planning;

Compartmentalisation of the island by restoring and strengthening old dikes;

In houses in unembanked areas, flood proofing measures have been taken (e.g. no carpet on the ground floor)

Use of early warning systems to predict river floods and storm surges

Redesign of existing buildings (schools/hotels) as shelters;

Building of additional new smart shelters;

Lifting or protecting vital infrastructure in zones outside the main dike ring;

Inhabitants of houses which flood regularly learned how to equip and furnish their house to minimise damage and recover quickly;

Inhabitants and authorities work together in disaster management (closable barriers, sand bags);

Preparing inhabitants and authorities for evacuation;

Creation of elevated evacuation routes (to evacuate $75 \%$ of the residents in the western and southernmost compartments to the safe north-eastern part of the island in case of a flood).

5. Flood recovery
Public financial compensation system at national level is in place under the 1998 Calamities and Compensation Act (WTS)

\subsection{Explaining Stability and Dynamics in Flood Risk Governance Arrangements in Dordrecht}

The emerging broadening of FRMSs and FRGAs in Dordrecht seems to logically follow from developments that have been taking place for some time. The vulnerable geographical location of Dordrecht (physical circumstances) combined with existing infrastructures - dikes through the old city centre, the presence of inhabitants in unprotected areas, the maintenance situation of existing dikes - are all the consequence of incremental developments in the past. However, the combination of these factors, against the backdrop of climate change effects, has resulted in Dordrecht taking up a very proactive role in flood risk governance, something which is unique for Dutch municipalities. The fact that Dordrecht has actually taken steps on a path towards such diversification is not self-evident, as several barriers against such a shift are present. These barriers include existing safety norms (social infrastructure, including substantive rules), but also existing divisions of responsibilities and financing structures (social infrastructure, including rules of the game and resources). Drivers for change, on the other hand, include that it is part of one of the regional sub-programmes of the Delta Programme, providing financial resources as well as scientific expertise (social infrastructure). Other drivers are the local support of the municipality - including the presence of a pro-active and (according to the authors) visionary policy maker (agency, policy entrepreneurs) and the municipality's positive experiences in participatory processes with residents.

\subsection{Evaluating Dynamics in Flood Risk Governance in Dordrecht}

Based on the analysis hitherto, Dordrecht seems to be an example in which a diversification of FRMSs can lead to enhanced resilience. As it is difficult for Dordrecht to significantly lower 

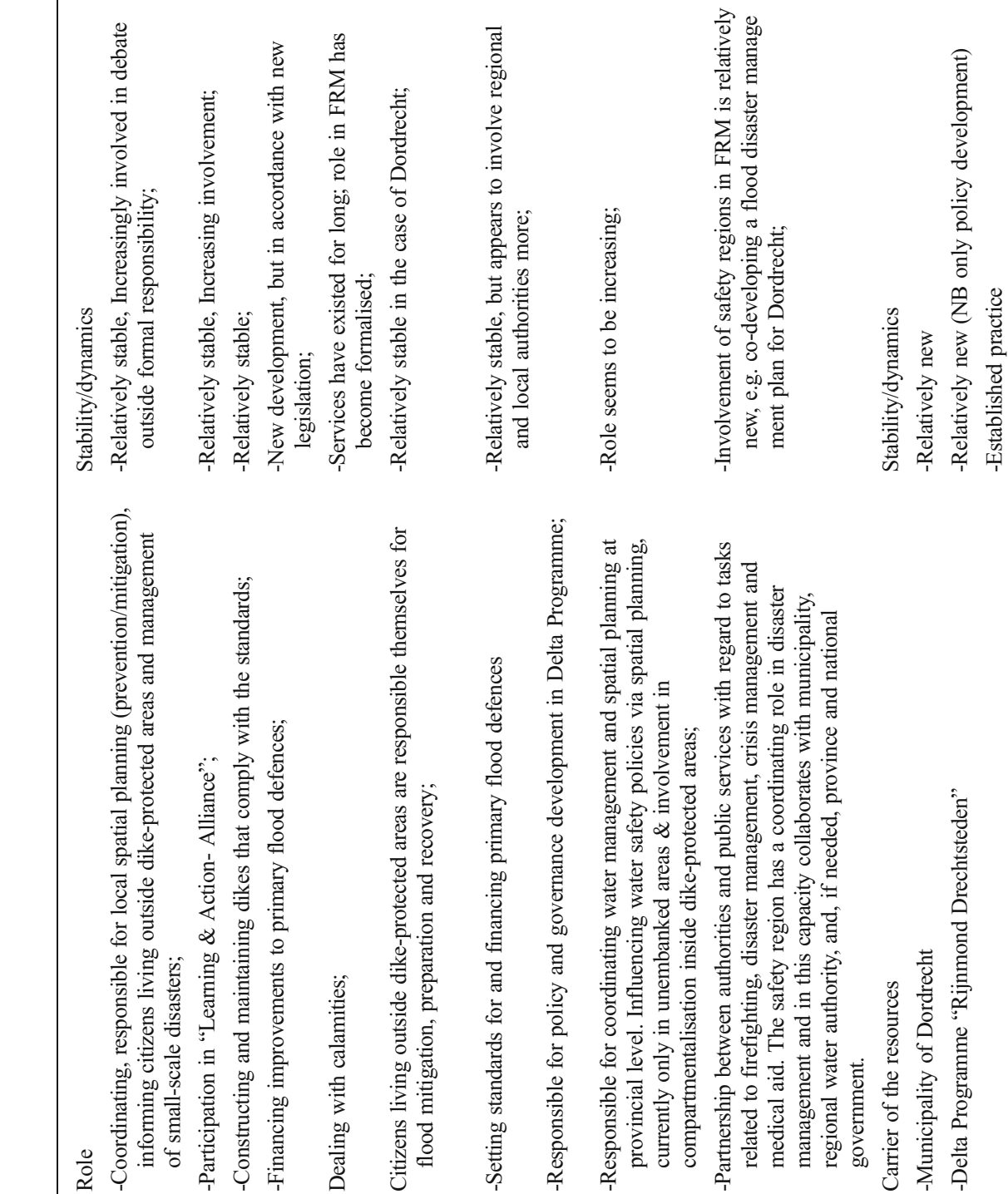

密

का 츨

远范

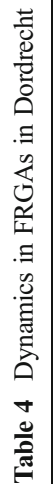
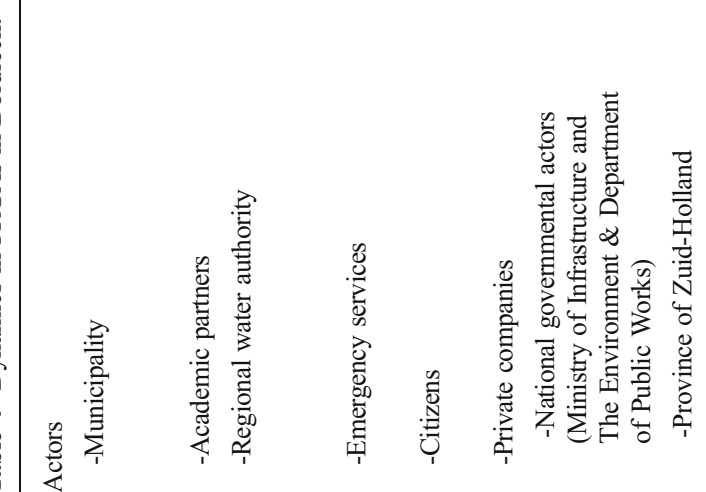

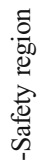

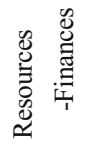




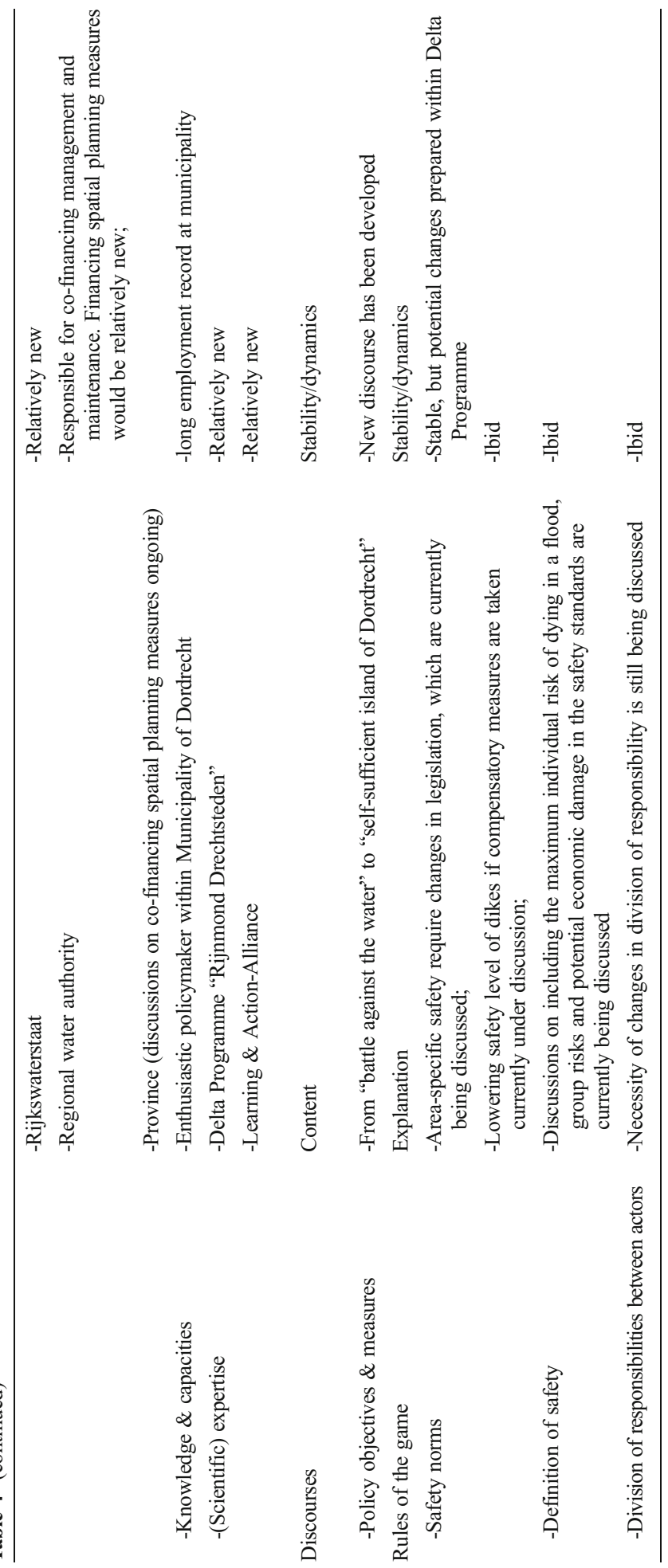


the probability of flooding on the whole island, the new self-sustaining strategy increases resilience by decreasing the potentially devastating consequences of a flood. The approaches in Dordrecht at first sight also seem to be effective, both in terms of goal achievement and in terms of governments and citizens having the necessary instruments at their disposal to reach these goals. About legitimacy we can say that the approaches followed in Dordrecht seem to be endorsed by the actors involved, including residents. Therefore output legitimacy (i.e. acceptance) (Van Buuren et al. 2013) can be assumed to be high. Finally, we can say that the shift from general to area-specific safety standards as well as the use of many smart combinations of FRMSs as specified in 7.2 seems to be a way to make flood risk management more efficient, at least to the impression of those most heavily involved.

\section{Concluding Remarks}

The previous sections have introduced a research approach for identifying Flood Risk Management Strategies and analyzing, explaining and evaluating Flood Risk Governance Arrangements. Its usefulness was illustrated by referring to the Dutch discourse on multilayered safety and its application in the city of Dordrecht. The approach introduced in this paper offers a useful starting point for researching Flood Risk Governance Arrangements. The approach, furthermore, enables the combination - and possibly integration-of various strands of expertise. It brings together public administration and legal expertise, but also allows the combination of descriptive, explanatory and more evaluative strands of policy theories.

As was stated in the introduction section, insights derived from using the approach may contribute to the formulation of concrete recommendations for achieving resilient, legitimate, efficient and effective flood risk governance. From the case of Dordrecht, we could derive some specific interventions, of which it is plausible that they are contributing to an on-going broadening of FRMSs including:

- the municipality's sustained cooperation with various knowledge institutes in a Learning and Action Alliance (actors dimension);

- the presence of a highly dedicated civil servant who can be labelled as a policy entrepreneur (actors/resources);

- discussions on the combination of different strategies (discourses);

- the potential shift from general to area-specific safety standards (rules of the game);

- past investments of the municipality in building and maintaining a good relationship with its citizens (in order to enhance legitimacy) (resources);

- possible availability of earmarked funding from the national government and regional water authorities for enhancing Flood Risk Management practices (resources).

A next step will be further confrontation of the approach with the empirics through collaborative research (Raadgever et al. 2012) to be able to further operationalize the concepts presented in this paper and to carry out comparative case study analyses in different countries. Such a comparison will help identifying examples of (less) successful broadening of FRMSs and drawing lessons regarding their generalizability.

We invite other scholars to adopt our approach. Although we specifically tailored the approach to the analysis, explanation and evaluation of flood risk governance, we do foresee possibilities for its application in other empirical domains as well. 
Acknowledgments This paper has been written in the framework of the European Union's Seventh Programme for Research, Technological Development and Demonstration within the STAR-FLOOD project. This research has received funding from the European Commission under grant agreement no. 308364. We would also like to thank the participants of the STAR-FLOOD consortium workshop in Amsterdam on 12 February 2013 which contributed to a refinement of the approach presented in this paper, Ellen Kelder and Berry Gersonius for their detailed insights on flood risk governance in Dordrecht, Ton Markus for producing the figure illustrating Dordrecht's vulnerability to flooding as well as Tina New stead for her language corrections.

\section{References}

Adger N, Brown K, Fairbrass J, Jordan A, Paavola J, Rosendo S, Seyfang G (2003) Governance for sustainability: towards a thick analysis of environmental decision-making. Environ Plan A :1095-1110

Aerts JCJH, Botzen W, Van der Veen A, Krywkow J, Werners S (2008) Dealing with uncertainty in flood management through diversification. Ecol Soc 13(1):41-57

Araral E, Wang Y (2013) Water Governance 2.0: a review and second generation research agenda. Water Resour Manag 27:3945-3957

Arts B, Leroy P, Van Tatenhove J (2006) Political modernisation and policy arrangements: a framework for understanding environmental policy change. Public Organ Rev 6(2):93-106

Barredo JI (2007) Major flood disasters in Europe: 1950-2005. Nat Hazards 42(1):125-148

Brouwer S, Biermann F (2011) Towards adaptive management: examining the strategies of policy entrepreneurs in Dutch water management. Ecol Soc 16(4):5

Capano G, Howlett M (2009) Introduction: the determinants of policy change: advancing the debate. J Comp Pol Anal 11(1):1-5

Davoudi S, Shaw G, Jamila Haider L, Quinlan AE, Peterson GD, Wilkinson C, Fünfgeld H, McEvoy D, Porter L, Davoudi S (2012) Resilience: a bridging concept or a dead End? "reframing" resilience: challenges for planning theory and practice interacting traps: resilience assessment of a pasture management system in northern Afghanistan urban resilience: what does it mean in planning practice? resilience as a useful concept for climate change adaptation? the politics of resilience for planning: a cautionary note. Plan Theory Prac 13(2):299-333

Dieperink C (2000) Successful international cooperation in the Rhine catchment area. Water Int 25(3):347-355

Djordjevic S, Butler D, Gourbesville P, Ole M, Pasche E (2011) New Policies to deal with climate change and other drivers impacting on resilience to flooding in urban areas: the CORFU approach. Environ Sci Pol 14: $864-873$

Downs A (1972) Up and down with ecology: the issue attention cycle. Public Interes 28:38-50

Driessen PPJ, De Gier A (1999) Flooding, river management and emergency legislation - experiences of the accelerated reinforcement of dikes in the Netherlands. J Econ Soc Geogr 90(3):336-342

Folke C (2006) Resilience: the emergence of a perspective for social-ecological systems analyses. Glob Environ Chang 16(3):253-267

Gersonius B, Hulsebosch M, Kelder E (2012) Concept gebiedsrapportage eiland van Dordrecht. Deltaprogramma Rijnmond Drechtsteden, Dordrecht

Giddens A (1984) The constitution of society. Polity Press, Cambridge

Green C, Viavattene C, Thompson P (2011) Guidance for assessing flood losses, CONHAZ report, CONHAZ report. Flood hazard research centre. Middlesex University, London

Guha-Sapir D, Hoyois P, Below R (2013) Annual disaster statistical review 2012: The numbers and trends. CRED, Brussels

Hartmann T, Driessen PPJ (2014) The flood risk management plan: towards spatial water governance. J Flood Risk Manag. doi:10.1111/jfr3.12077

Hegger DLT, Green C, Driessen PPJ, Bakker M, Dieperink C, Crabbé A, Deketelaere K, Delvaux B, Suykens C, Beyers JC, Fournier M, Larrue C, Manson C, Van Doorn-Hoekveld W, Van Rijswick M, Kundzewicz ZW, Goytia Casermeiro S (2013) Flood risk management in Europe: Similarities and differences between the STAR-FLOOD consortium countries. STAR-FLOOD Consortium, Utrecht

Hoss F (2010) A comprehensive assessment of Multilayered safety (Meerlaagsveiligheid) in flood risk management. Master thesis, Delft University of Technology

Hughes TP (1987) The evolution of large technological systems. In: Bijker WE, Hughes TP, Pinch T (eds) The social construction of technological systems: new directions in the sociology and history of technology. MIT Press, Cambridge, pp 51-82

Huitema D, Meijerink S (2010) Realizing water transitions: the role of policy entrepreneurs in water policy change. Ecol Soc 15(2):26 
IPCC (2011) Summary for policymakers of intergovernmental panel on climate change special report on managing the risks of extreme events and disasters to advance climate change adaptation. Cambridge University Press, Cambridge

Keessen AM, Van Rijswick HFMW (2012) Adaptation to climate change in European water Law and policy. Utrecht Law Rev 8(3):38-50

Keessen A, Hamer MJM, Van Rijswick HFMW, Wiering M (2013) The concept of resilience from a normative perspective: examples from Dutch adaptation strategies. Ecol Soc 18(2):45

Kellens W, Vanneuville W, Verfaillie E, Meire E, Deckers P, De Maeyer P (2013) Flood risk management in Flanders: past developments and future challenges. Water Resour Manag 27:3585-3606

Kingdon J (1984) Agendas, alternatives, and public policies. Little, Brown, Boston

Klijn F, De Bruijn K, Ölfert A, Penning-Rowsell E, Simm J, Wallis M (2009) Flood risk assessment and flood risk management; an introduction and guidance based on experiences and findings of FLOODsite (an EUfunded integrated project). FLOODsite consortium

Kunreuther H (2008) Reducing losses from catastrophic risks through long-term insurance and mitigation. Soc Res 75(3):905-930

Meijerink S, Dicke W (2008) Shifts in the public-private divide in flood management. Int J Water Res Dev 24(4): 499-512

Mitchell JK (2003) European river floods in a changing world. Risk Anal 23(3):567-574

Oosterberg W, Van Drimmelen C, Van der Vlist M (2005) Strategies to harmonize urbanization and flood risk management in deltas. In: 45th Congress of the European Regional Science Association, Vrije Universiteit Amsterdam pp. 23-27

Ostrom E (1990) Governing the commons: The evolution of institutions for collective action. Cambridge University Press, New York

Paavola J (2008) Science and social justice in the governance of adaptation to climate change. Environ Polit 17(4):644-659

Pahl-Wostl C (2009) A conceptual framework for analysing adaptive capacity and multi-level learning processes in resource governance regimes. Glob Environ Chang 19(3):354-365

Programmateam Rijnmond-Drechtsteden (2012) Deltaprogramma 2013: Probleemanalyse Rijnmond Drechtsteden. Deltaprogramma Rijnmond-Drechtsteden

Quevauviller P (2011) Adapting to climate change: reducing water-related risks in Europe - EU policy and research considerations. Environ Sci Pol 14:722-729

Raadgever GT, Mostert E, Van de Giesen NC (2012) Learning from collaborative research in water management practice. Water Resour Manag 26:3251-3266

Sabatier P, Weible CM (2007) The advocacy coalition framework: Innovations and clarifications. In: Sabatier PA (ed) Theories of the policy process. Westview Press, Davis, pp 189-220

Steinführer A, Kuhlicke C, De Marchi B, Scolobig A, Tapsell S and Tunstall S (2009) Local communities at risk from flooding. Social vulnerability, resilience and recommendations for flood risk management in Europe. Final report for FLOODsite, Winterwork, Grimma

Van Buuren A, Driessen PPJ, Teisman G, Van Rijswick M (2013) Toward legitimate governance strategies for climate adaptation in The Netherlands: combining insights from a legal, a planning and a network perspective. Reg Environ Change doi: http://dx.doi.org/10.1007/s10113-013-0448-0

Van den Brink M, Termeer C, Meijerink S (2011) Are Dutch water safety institutions prepared for climate change? J Water Clim Chang 2(4):272-287

Van Rijswick M, Havekes H (2012) European and Dutch water law. Europa Law Publishing, Groningen

Van Tatenhove J, Arts, Leroy P (2000) Political modernisation and the environment: the renewal of environmental policy arrangements. Kluwer Academic Publishers, Dordrecht

Wardekker JA, De Jong A, Knoop JM, Van der Sluijs JP (2010) Operationalising a resilience approach to adapting an urban delta to uncertain climate changes. Technol Forecast Soc 77(6):987-998

Wiering, MA (2008) Shock waves and institutional change, chains of events and events of change, the role of shock events in policy change. Freude am Fluss conference. Radboud University Nijmegen

Wiering M, Arts B (2006) Discursive shifts in Dutch water management: 'Deep' institutional change or adaptation strategy? Hydrobiol 565(1):327-338 